\title{
Instituições fazem diferença: o caso da reforma do sistema eleitoral em Israel
}

Artur Zimerman

Resumo

Este artigo tem por intuito demonstrar que as instituições fazem diferença, $e$ às vezes muita diferença. $\mathrm{O}$ estudo de caso da mudança do sistema eleitoral israelense revela um dano irreversível ao país, impossibilitando-o de mudar seu rumo político. Os dois maiores partidos na época impulsionaram a mudança, o que os prejudicou posteriormente. O sistema que estava instalado até então era prejudicial ao país, mas as modificações dele provaram serem piores que seus próprios precursores para o país em geral. A conclusão a que se chega é de que boas intenções podem levar a maus resultados.

Seguindo as palavras do cientista político Lijphart, concordamos que "um sistema eleitoral é o elemento fundamental da representação democrática, traduzindo votos dos cidadãos em representações políticas". ${ }^{1}$ A mudança de um sistema a outro pode provocar sérias conseqüências e até mudar o rumo dos acontecimentos. $\mathrm{O}$ caso que trataremos neste trabalho se refere à mudança de sistema eleitoral em Israel.

Em março de 1992 houve uma reforma eleitoral que começou a vigorar a partir das eleições de maio de 1996. O motivo da mudança

1 Lijphart, A. Electoral Systems and Party Systems: A Study of Twenty-Seven Democracies 1945-1990. UK: Oxford University Press, 1994, p. 1. 
era a insatisfação geral causada pelo performance do governo, no qual a não-governabilidade era grande devido à força crescente dos pequenos partidos, principalmente em relação aos recursos desproporcionais que estes recebiam na formação de governo e nas políticas públicas (tanto em cargos quanto em políticas), e ao limitado poder do primeiro-ministro.

Uma reforma institucional era necessária para resolver estas questões, onde a instabilidade governamental extrapolava. Para se ter uma idéia, em 48 anos foram 26 governos diferentes, uma média de um governo a cada 1.8 anos, uma das menores médias em governos parlamentaristas*.

Desde sua fundação até 1977 o partido Mapai (que deu origem ao Partido Trabalhista) era dominante no Parlamento israelense, variando entre $37.5 \%$ - 46.7\% das cadeiras. ${ }^{2}$ A partir de 1977 o Likud, originário do Herut, juntamente com o Partido Trabalhista eram os dois maiores partidos. O primeiro juntando-se a partidos (judaicos) menores de direita, e o segundo a partidos de esquerda menores, tanto árabes como judeus. Estava montado o cenário da polarização do Parlamento israelense (Knesset), e da alternância no poder.

Os partidos religiosos menores funcionavam como partidos pivotais, equilibrando os dois lados, juntando-se a quem oferecesse melhor payoff. De acordo a Lijphart, o número médio de partidos do Parlamento israelense em todo o período até a reforma eleitoral era de $4.42^{*}$, colocando-se na mesma classificação como Holanda, Dinamarca, Bélgica, Itália e Finlândia, um dos maiores índices do parlamentarismo. ${ }^{3}$ Porém, veremos que as preferências individuais dos eleitores, as quais supostamente deveriam levar às preferências sociais, através das instituições (regras e práticas onde as decisões coletivas são tomadas) deveriam dar resultados sociais vantajosos. Porém, na prática isso não ocorre. O inverso é a regra, que será demonstrado neste caso específico.

2 Stoll, Heather, Taking Regime Type Seriously: Theories of Party Sistems Revisited. Standford, 2001, p. 34-5.

3 Ibid., p. 76. 


\section{A era pré-reforma}

Entre 1951-1992 Israel possuía um dos sistemas proporcionais parlamentaristas mais puros existentes, onde Israel inteiro era um grande distrito $e$ as cadeiras de cada partido no Parlamento eram diretamente proporcionais ao número dos votos obtidos**. O mínimo de votos para que o partido ganhe a primeira cadeira entre 1951-1992 era de $1.0 \%$ (a partir de 1992 passou a ser 1.5\%), baixo índice se comparado a outros países.

Os candidatos a primeiro-ministro deveriam ser membros do Parlamento, além de líderes dos maiores partidos, sendo este escolhido através do voto de investidura parlamentar.

O processo decisório é centralizado. Há uma multiplicidade de partidos, onde nunca houve um partido que ganhasse a maioria do Parlamento. Por isso há necessidade de uma árdua barganha para a formação do governo, um processo que geralmente envolve um partido maior (Trabalhista ou Likud) com vários partidos menores para formar maioria.

Office-seeking e policy-seeking são utilizados para satisfazer a todos num curto prazo e formalizar a formação do governo com o necessário voto de investidura. Há também os payoffs paralelos para compensar perdas nas políticas quando a distância ideológica entre os partidos no governo é grande. Porém, mesmo com elevados payoffs, a médio-largo prazo geralmente a coalizão não consegue se sustentar por haver muita divergência entre os diferentes partidos do governo em relação à política, e assim a divisão de cargos não é suficiente, e o governo é derrubado.

Os partidos policy-seeking podem entrar no governo, se assim eles puderem influenciá-lo de dentro (eles podem também ficar de fora se sentirem que podem ditar a política permanecendo em posição pivotal no Legislativo), e os partidos office-seeking podem barganhar política, se eles acharem que isso os fará ganhar votos na próxima eleição. ${ }^{4}$

Essa é uma característica dos sistemas multipartidários, e Israel situa-se em seu extremo, sendo uma sociedade com um alto grau de conflitos intra-societários. Como o Legislativo geralmente é uma mini-

4 LaVer, M., Schofield, N., Multiparty Government: The Politics of Coalition in Europe. Univ. of Michigan Press, 1990, p. 61. 
atura da sociedade, reproduzindo-a, a polarização característica do Parlamento israelense faz com que as coligações sejam difíceis de serem alcançadas, e quando as são, comportam-se de maneira instável.

Por um lado esse número elevado de partidos permite uma representatividade alta de interesses diversos da população, mas por outro, cria uma complexidade na formação do governo. ${ }^{5}$

\section{A era pós-reforma}

A proposta inicial para mudar o sistema eleitoral em Israel começou nos anos 80, através de uma "comissão pública", onde se apoderaram líderes dos dois maiores partidos, e com uma boa campanha $e$ elevados recursos conseguiu-se atingir a opinião pública, mudando o sistema. Ele passou de um sistema proporcional puro para sistema "quase-presidencial", onde o chefe do Executivo é eleito por voto direto, independentemente do Legislativo.

Porém, há divergências entre vários autores quanto à classificação do regime democrático em Israel pós-1992. Enquanto Shugart \& Carey (1992) o classificam de "presidencial-parlamentar", Lijphart (1999) o enquadra primeiramente como "presidencialista", classificando-o de "Híbrido VI" (categoria singular, onde não há outro exemplo em que o Executivo é escolhido pelos eleitores, porém o primeiro-ministro depende do voto de confiança do Legislativo), Sartori (1997) o classifica (tanto Israel como França) como "semi-presidencial", e Stoll (2001) o classifica como único, não sendo nem presidencialista, nem parlamentarista, nem semi-presidencialista. ${ }^{6}$ Vemos a problemática de classificação deste tipo único de regime. Para a população em Israel, o regime continua parlamentarista - é assim que o povo o conhece.

Se formos seguir a análise de Tsebellis (1995), ele afirma que em sistemas parlamentaristas o Executivo (governo) controla a agenda, $e$ o Legislativo (Parlamento) aceita ou rejeita propostas, enquanto que em sistemas presidencialistas o Legislativo faz a proposta e o Executivo

5 MAHLER, Gregory, Israel's New Electoral System: Effects on Policy and Politics, Middle East Review of International Affairs, 1(2), July 1997, meria.idc.ac.il.

6 Op. Cit., Stoll, p. 16-7. 
(presidente) a aprova ou a veta. ${ }^{7}$ Raciocinando por este ângulo, apesar das reformas em Israel, ele continua sendo parlamentarista. E, se a essência da democracia parlamentar é a prestação de contas (accountability) do governo ao Legislativo, como argumentam Laver e Shepsle ${ }^{8}$ (1996), Israel assim se comporta. Apresentando estas divergências múltiplas, darei seguimento ao trabalho, deixando em aberto essa discussão da real classificação de regime em Israel pós-1992.

Duas mudanças principais que supostamente fortaleceriam o primeiro-ministro ocorreram:

1. Votação direta a primeiro-ministro, além de votação com lista fechada ao partido. Cada eleitor vota com duas cédulas, uma elegendo o primeiro-ministro e outra o partido (podendo ser outro que não o do candidato a primeiro-ministro).

2. Voto de confiança não mais seria como antes, onde precisava de apenas maioria presente no plenário para passar (o qual só derrubava o primeiro-ministro e seu governo, porém não dissolvia o Parlamento), tanto é que em Israel houve 15 eleições gerais e 29 governos diferentes. A partir da reforma, necessitava-se de maioria absoluta de parlamentares, ou seja, 61 dos 120 membros, para que o primeiro-ministro renunciasse e o Parlamento fosse dissolvido com sua saída, salvo quando haja pelo menos 80 dos 120 membros contra o governo, pois neste caso o Parlamento não se dissolve.

Em relação à primeira mudança, ela permitiu que o primeiroministro pudesse não coincidir com o partido majoritário (o que ocorreu apenas uma vez na história eleitoral de Israel até então, onde o presidente escolhia o partido que seria o formateur). De fato, em 1996 o primeiro-ministro eleito diretamente, Netaniahu, não foi o líder do maior partido, o qual obteve duas cadeiras a menos que o Partido Trabalhista de Peres. Isso reincidiu durante a eleição de 2001 entre Barak e Sharon, onde o Partido Trabalhista de Barak era majoritário e

7 Cheibub, J. A.; Limongi, F. Democratic Institutions and Regime Survival: Parliamentary and Presidential Democracies Reconsidered, p. 17.

8 Laver, M.; Shepsle, K. A. Making and Breaking Governments: Cabinets and Legislatures in Parliamentary Democracies. NY: Cambridge Univ. Press, 1996, p. 3. 
perdeu as eleições de primeiro-ministro para Sharon. Portanto, o partido majoritário não mais representava automaticamente (através do aval do presidente) o governo.

Em relação à segunda mudança, ela acarretou indisposição dos parlamentares pois estes não tem segurança se serão reeleitos numa próxima eleição, e para Downs, o objetivo de todo político é se reeleger, maximizando seus votos na próxima eleição. ${ }^{9}$ Porém, se o político pode ficar maior tempo sem o risco que envolve a reeleição, melhor. Para que o primeiro-ministro saia e a coalizão termine sem que o Parlamento seja dissolvido, há necessidade de 80 dos 120 votos disponíveis, algo difícil de ser alcançado, principalmente numa sociedade tão diversa e conflituosa. Cheibub, Przeworski e Saiegh (2001) afirmam que a única diferença entre o parlamentarismo e o presidencialismo é que no primeiro é agendada uma nova eleição em situações em que a maioria do Parlamento se opõe ao Executivo no presidencialismo. ${ }^{10}$ Porém, como este é um regime democrático que foge à regra quanto à sua classificação, esta regra não cobre o caso específico.

Na eleição de 2001, depois de 18 meses de governo, Ehud Barak convocou novas eleições sentindo que precisava de apoio da população, já que o programa de paz que ele almejou com os palestinos foi por água abaixo. Ele continuou sendo o candidato a primeiro-ministro por parte do Partido Trabalhista.

Para favorecer ao possível candidato Netaniahu (ex-primeiroministro, que não era membro do Parlamento até o dia da eleição), a Knesset mudou a lei no sentido de que o candidato a primeiro-ministro não necessitasse ser membro do Parlamento. Apesar disso, Netaniahu não se candidatou, dando como condição a convocação de eleição geral, pois ele queria que o peso no Parlamento mudasse a seu favor, o que não lhe foi possibilitado, ocupando a liderança partidária em seu lugar Sharon. Desde a derrota de Netaniahu para Barak (1996), este abandonou o Parlamento e deixou a liderança do partido Likud a Airel Sharon, que foi candidato a primeiro-ministro concorrendo com Ehud Barak.

9 Shepsle, K., Bonchek, M., Analysing Politics, 1997, p. 31.

10 Cheibub, J. A., Przeworski, A, Saiegh, S., "Government Coalitions under Presidentialism and Parlamentarism". Presented at Conference on Brazilian Political Institutions in Comparative Perspective: The Role of Congress in Presidential Systems, Centre for Brazilian Studies, Oxford University, 2001, p. 1. 
Os candidatos a primeiro-ministro devem ter no mínimo 30 anos de idade e serem nomeados por um partido (ou por partidos coligados que concorram numa só plataforma) com no mínimo 10 cadeiras no Parlamento. O candidato precisa receber mais que $50 \%$ de todos os votos válidos. Caso contrário, há um segundo turno com os dois que receberam o maior número de votos, vencendo o que obter mais votos dos dois. Caso o candidato eleito não consiga formar um governo em 45 dias após sua eleição, outra eleição (somente para primeiro ministro) é convocada. Se até a terceira eleição convocada consecutivamente ele não formar o governo, o candidato não poderá participar da eleição seguinte. Não há voto de abstenção nesta eleição, porém o voto não é obrigatório.

O Parlamento fornece 10 milhões de dólares para campanha de cada candidato. Se o candidato conseguir menos que $8 \%$ dos votos, deve devolver toda a soma ao Parlamento. Se conseguir até $15 \%$, ele deve devolver metade do valor. Isto para evitar que um número excessivo de candidatos concorram.

Os defensores da reforma argumentavam que ela iria deixar o primeiro-ministro menos dependente dos outros partidos, especialmente dos partidos religiosos, os quais regularmente "chantageavam" o governo devido às suas posições de partidos pivotais, obtendo benefícios públicos para as instituições religiosas.

O espaço político da Knesset é representado no seguinte organograma:

\begin{tabular}{|c|c|c|c|c|c|c|}
\hline & & & centro & & & \\
\hline $\begin{array}{l}\text { Partidos } \\
\text { comunistas } \\
\text { árabes e }\end{array}$ & $\begin{array}{l}\text { Partido de } \\
\text { esquerda } \\
\text { Meretz }\end{array}$ & $\begin{array}{l}\text { Partido } \\
\text { Traba- } \\
\text { lhista }\end{array}$ & $\begin{array}{l}\text { Partidos } \\
\text { religiosos } \\
\text { ortodoxos }\end{array}$ & $\begin{array}{c}\text { Partido } \\
\text { Likud }\end{array}$ & $\begin{array}{c}\text { Partidos } \\
\text { religiosos } \\
\text { nacionalistas }\end{array}$ & $\begin{array}{c}\text { Partidos } \\
\text { de ultra- } \\
\text { direita }\end{array}$ \\
\hline
\end{tabular}

Shepsle e Bonchek afirmam que o ponto ideal do eleitor mediano é preferido pela maioria a qualquer outro ponto. ${ }^{11}$ Porém, dado à polarização do sistema eleitoral Israelense, os pontos ideais se dividiam (e alternavam) em dois (partidos Trabalhista e Likud). Ocorreu uma mudança espacial nos pontos ideais do eleitor mediano. Como a reforma polarizou ainda mais o Parlamento (refletida na votação ao parti-

11 Op. Cit., Shepsle e Bonchek, p. 89. 
do, e não ao candidato a primeiro-ministro) os eleitores passaram do voto estratégico ao sincero, alterando o equilíbrio de forças dentro da Knesset, como podemos observar no esquema da próxima página.

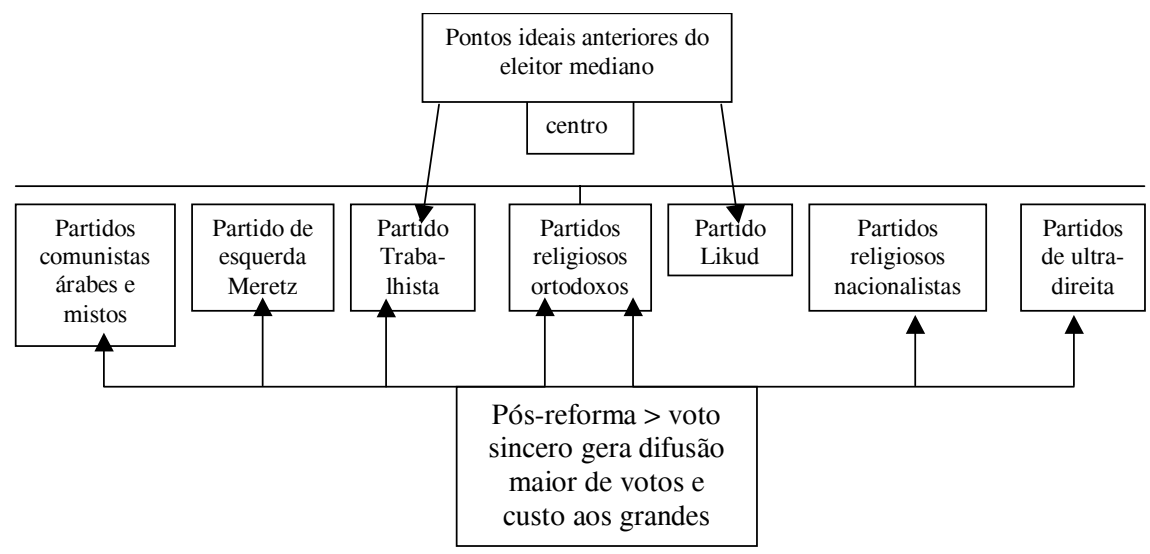

Usamos o modelo espacial unidimensional para simplificar a esquematização, porém sabemos que o modelo multidimensional é o que mais se adapta a realidade do sistema eleitoral de Israel, onde várias dimensões ideológicas podem ser representadas. Lijphart (1990) enumera diferentes dimensões ideológicas presentes no sistema democrático partidário desde os anos 70 , através dos 80 , e a meu ver, muitos se conservam até hoje. Ele cita as dimensões sócio-econômica, religiosa, cultural-étnica, urbana-rural, apoio a regime, política externa, pós-materialismo. ${ }^{12}$ Para a realidade de Israel, as dimensões relevantes são: sócio-econômica, religiosa, cultural-étnica, política externa. Portanto, abaixo diagramamos multidimensionalmente as situações anterior e posterior à reforma.

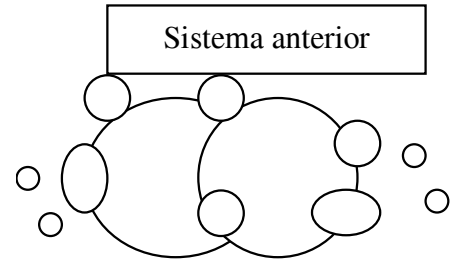

O

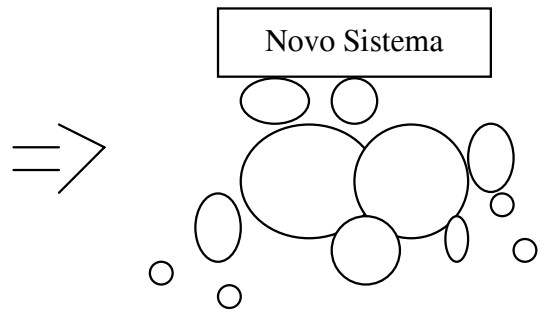

O

12 Lijphart, A., Dimensions of Ideology in European Party System. In: MaIR ED, Peter. The West European Party System. UK: Oxford Univ. Press, 1990, p. 254. 
Esta figura nos mostra o que a mudança de sistema eleitoral causou a divisão de cadeiras no Parlamento e a dependência dos pequenos em relação aos grandes partidos. No novo sistema eleitoral o voto sincero causou uma significativa redução dos dois grandes partidos em benefício dos pequenos, além de uma certa independência dos pequenos em relação aos grandes, que se fortaleceram mais. Enquanto que os pontos ideais dos eleitores medianos eram mais nítidos no sistema eleitoral antigo, houve uma difusão grande no novo sistema, ocasionando problemas maiores no momento da formação do governo, já que a polarização é bem mais dispersa e significativa que a situação anterior.

Vimos então que agora o partido do primeiro-ministro eleito pode não ser o maior no Parlamento. O que o diferencia do presidencialismo é que, em Israel, se o primeiro-ministro não consegue formar coalizão de governo, haverá até três eleições consecutivas até ele conseguir formá-lo, e no presidencialismo o presidente eleito ficará até o fim do mandato, mesmo que não possua maioria e que, na prática, a oposição governe de facto.

Além disso, a maioria necessária para convocar novas eleições para primeiro-ministro sem ocasionar eleições para o Parlamento passa a ser de 80 parlamentares. Eleição a primeiro-ministro pode ser convocada também em casos que o primeiro-ministro é removido do cargo pelo Parlamento por ser considerado moralmente inapto ao cargo, ou ele não consegue formar um governo de, no mínimo, 8 ministros durante os 45 dias concedidos para tal, ou se o primeiro-ministro morre ou não se encontra em condições de exercer o cargo.

\section{Porque falhou a reforma?}

Nachmias e Sened (1998) mostram que a reforma institucional na lei eleitoral reduziu a força dos grandes partidos e aumentou o poder de barganha dos pequenos (mais significativamente dos religiosos). Para os favoráveis à reforma, os resultados da mudança foram contra-intuitivos, porém, se analisarmos a situação, era de se esperar estes resultados. ${ }^{13}$

13 ElAZAR, Daniel J. "Electoral Reform for Israel: A Realistic Proposal”, www.jcpa.org/ djeindex.htm, Jerusalem Center for Political Affairs. 
Concordamos com Nachmias e Sened, ${ }^{14}$ os quais encontraram três problemas principais da reforma eleitoral que, além de não sanar as carências do sistema anterior, acarretaram danos ainda maiores ao sistema eleitoral israelense. Eles são:

- Objetivo da mudança: fortalecimento dos dois maiores partidos

1. A nova lei dá aos pequenos partidos três períodos onde estes pressionam os grandes - antes do primeiro turno das eleições, antes do segundo turno das eleições e durante a formação de governo, ao contrário de antes da reforma, onde essa pressão só existia no período de formação do governo.

Após as reformas, a barganha dos partidos pequenos é feita com os candidatos a primeiro-ministro (em dois turnos, se houver o segundo) e na própria formação, como antes. Um exemplo disso aconteceu na eleição de 1996, onde Netaniahu ganhou de Peres por uma margem de $0,99 \%$ (com 50,49\%), isto porque foram feitos acordos anteriores à eleição entre Netaniahu e outros dois candidatos de partidos menores (Eitan, do Tzomet, e Levy, do Guesher), que possibilitou não haver segundo turno para primeiro-ministro. Além disso, esses acordos implicaram perda de 7 cadeiras "seguras" do Likud para o Tzomet $e$ outras 7 cadeiras "seguras" do Likud para o Guesher. Assim o Likud se enfraqueceu muito, mesmo ganhando as eleições para primeiro-ministro, o que não aconteceria se um dos dois ex-candidatos não desistissem, pois seus eleitores sairiam do próprio Likud, e a diferença entre Netaniahu e Peres era mínima, ${ }^{15}$ como se comprovou na contagem dos votos.

Diz-se que Netaniahu "enfraqueceu" seu próprio partido para ganhar a eleição. Esse tipo de pressão não poderia existir no sistema eleitoral antigo, além de que Peres ganharia as eleições no sistema anterior, pois era o líder do maior partido. Os partidos pequenos continuavam a "chantagear" os grandes aumentando seu poder de barganha, o que foi contrário ao que se pretendeu com a mudança.

14 Nachmias, David, Sened, Itai, "Electoral Reform in Israel", www.aceproject.org/ main/english/es/esy_il.htm, 1997.

15 Op. Cit., Mahler. 
- Objetivo da mudança: enfraquecimento e possível desaparecimento dos pequenos partidos

2. A reforma possibilitou que os eleitores votassem mais que antes aos partidos pequenos, pois como as eleições são diretas ao primeiro-ministro, e este forma o governo, não há mais necessidade do voto estratégico por parte dos eleitores, votando no maior partido para que este forme o governo, como quase sempre ocorria anteriormente. Atualmente os eleitores podem votar sinceramente para seus partidos, pois o voto estratégico vai para o formateur, ou seja, para o candidato a primeiroministro que formará o governo. Assim os maiores partidos perdem votos para os menores, e estes, por sua vez, se fortalecem, contrário ao pretendido anteriormente.

Como podemos verificar claramente nas duas representações que se seguem, o aumento de partidos no Parlamento (Knesset) do primeiro período $\left(1^{\circ}-13^{\circ}\right.$ Parlamento) ao segundo (pós-reforma, $14^{\circ}$ e $15^{\circ}$ Parlamento) foi contundente, ${ }^{16}$ não deixando dúvida nos resultados obtidos relativo à multiplicação de partidos.

\begin{tabular}{|l|c|c|}
\hline Knesset & Ano & $\mathrm{Np}$ \\
\hline 1 & 1949 & 4.73 \\
2 & 1951 & 4.83 \\
3 & 1955 & 6.00 \\
4 & 1959 & 4.92 \\
5 & 1961 & 5.37 \\
6 & 1965 & 4.72 \\
7 & 1969 & 3.57 \\
8 & 1973 & 3.35 \\
9 & 1977 & 4.37 \\
10 & 1981 & 3.13 \\
11 & 1984 & 3.86 \\
12 & 1988 & 4.38 \\
13 & 1992 & 4.41 \\
14 & 1996 & 5.61 \\
15 & 1999 & 8.74 \\
\hline
\end{tabular}

16 Fonte, nos dois casos: Stoll, Heather. Taking Regime Type Seriously: Theories of Party Sistems Revisited. Standford, 2001, p. 18-9. 
by Knesset

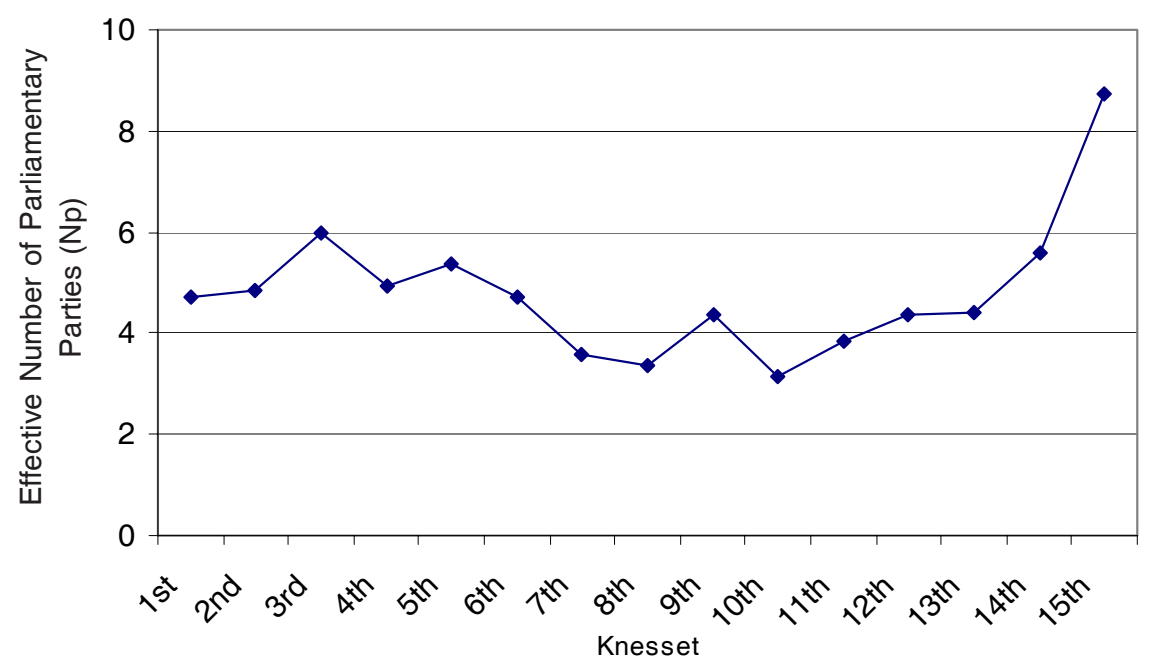

- Objetivo: reduzir a ocorrência do uso do voto de confiança, fortalecendo o primeiro-ministro

3. A mudança do voto de confiança alterou a capacidade de governabilidade das coalizões e a eficácia das oposições parlamentares. $\mathrm{O}$ voto de confiança serve geralmente para que o primeiro-ministro discipline a coalizão a votar com o governo, mesmo que não estejam de acordo. Na nova lei os parlamentares não tem incentivos de votarem contra o primeiro ministro no voto de confiança, pois isso os atingiriam diretamente, e assim, tanto o primeiro-ministro perde este recurso importante que tinha, como também a oposição fica enfraquecida diante do risco de novas eleições ao Parlamento. $\mathrm{O}$ voto de confiança perde seu poder de ameaça dos menores partidos em relação ao governo, enfraquecendo a oposição na necessidade de mais votos para a derrubada do primeiro-ministro.

É claro que antes da reforma, o uso do voto de confiança era excessivo, e independente do quorum de parlamentares presente, punha-se em risco a existência do governo. Essa era uma situação inaceitável, porém a reforma conseguiu prejudicar a situação ainda mais. 
O Parlamento israelense se enfraqueceu em relação ao período anterior à reforma, e os próprios argumentos proferidos por alguns parlamentares do Likud, de que é válido perder 14 candidatos "seguros" da lista do partido para que Netaniahu seja o primeiro-ministro provavam isso.

No parlamentarismo israelense, onde supostamente há a disciplina partidária (levando em consideração que os partidos quase sempre entram e deixam as coalizões como blocos unificados), ${ }^{17}$ o payoff para entrar na coalizão é maior proporcionalmente para pequenos partidos do que para grandes, pois haverá necessidade de mais partidos para completar o mínimo necessário a se obter maioria no Parlamento. Por exemplo, se 5 partidos com a maioria de 61 dos 120 membros formam a coalizão, o preço em office e policy será maior do que se um partido grande e um pequeno formarem a coalizão majoritária com o mesmo número de membros.

Portanto, na atual situação a reforma eleitoral fortaleceu os pequenos e enfraqueceu os grandes, exigindo payoffs maiores aos vários pequenos, além da inevitabilidade da instabilidade governamental, já que, quanto maior o número de partidos na coalizão, maior a instabilidade e pior a performance, o que já caracterizava Israel antes da reforma, vindo só a acentuar-se no período pós-reforma.

Hinch e Munger afirmam que a estabilidade do sistema político depende da distribuição e da natureza das preferências dos eleitores, como também das regras utilizadas a relacionar estas preferências às escolhas sociais. ${ }^{18}$ Sendo assim, as regras mudadas só fizeram aumentar a instabilidade que já caracterizava os governos até então. Aceitamos a idéia de que havia necessidade de uma reforma e a escolha social pressionava para que isso ocorresse. Porém, vimos que as preferências individuais racionais dos eleitores não resultaram numa escolha social coerente, como a que veio a ocorrer.

O problema não é apenas formar um governo, mas sim governar. E, apesar de não crer no caos de Mckelvey, há dois partidos (Trabalhista e Likud) que se alternam no poder, e são os partidos medianos (conforme teorema de Black). Porém, com esta reforma, os dois partidos medianos perderam parte do poder que tinham antes por enfra-

17 Op. Cit., Laver e Shepsle, 1996, p. 25.

18 Hinch, M. J.; Munger, M. M., Analytical Politics, p. 21. 
quecerem-se frente a partidos pequenos (zero-sum-game, enquanto uns ganham outros consequentemente perdem, já que há limite de 120 cadeiras no Parlamento israelense), assim debilita-se a posição dos partidos medianos. Por exemplo, em 1992 a coligação do Partido Trabalhista tinha 44 membros, caindo para 34 nas eleições seguintes de 1996, enquanto que a coligação do Likud possuía 40 membros em 1992, caindo para 32 em 1996. ${ }^{19}$ Hinch e Munger dizem que o poder político se situa no meio do espaço onde os eleitores se distribuem. ${ }^{20}$ Mas, se com a reforma esse poder se espalhou muito, e não está mais concentrado em alguns poucos focos de poder, diríamos que no caso de Israel a reforma contribuiu para um maior descontrole do governo em relação ao Parlamento, sem concentrar o poder necessário para tomar decisões e aprová-las posteriormente.

Além da coalizão formada, a durabilidade do governo entra em questão, como nos afirmam Laver e Schofield. ${ }^{21}$ Contudo, até o momento, devido ao curto espaço de tempo desde a reforma, não é possível afirmar empiricamente se haveria uma continuidade de governos curtos pós-reforma, no entanto tudo indica que esse é o caminho natural devido às circunstâncias descritas.

Vemos também que o fortalecimento dos pequenos partidos afina as divisões étnicas e religiosas/seculares na sociedade israelense, que já não eram poucas antes da reforma.

Essas divisões internas suscita uma pergunta que estudiosos do tema não conseguiram responder: por qual motivo todas essas divisões não influenciaram uma multiplicidade de candidatos ao Executivo desde a reforma (já que antes da reforma o líder do maior partido geralmente formava o governo, agora o caminho estava aberto para vários candidatos concorrerem a primeiro-ministro)? Apesar de nas últimas três eleições com voto duplo vários candidatos concorreram entre si, só sobravam dois até a véspera das eleições, como podemos verificar na tabela seguinte: ${ }^{22}$

19 Peters, Joel, "Under Netaniahu: The Current Situation i the Israeli Politics, Middle East Review of International Affairs, 1(1), January 1997, meria.idc.ac.il/journal/ 1997/issue1/jv1n1a2.html

20 Ibid., p. 31.

21 Op. Cit., Laver e Schofield, p. 12.

22 Tabela extraída de: Stoll, Heather, Taking Regime Type Seriously: Theories of Party Sistems Revisited, Standford Univ., Fall 2001, p. 26. 


Results for the direct prime ministerial elections
Percent of valid votes in first round
\begin{tabular}{|llll|}
\hline \multirow{4}{*}{ Netanyahu } & 1996 & 1999 & 2001 \\
Peres & 50.5 Netanyahu & 43.9 Barak & 37.6 \\
& 49.5 Barak & 56.1 Sharon & 62.4 \\
\hline
\end{tabular}

Outro assunto que suscita reflexão é o aumento de poder do primeiro-ministro (em uma sociedade com sérias divisões como em Israel) quando eleito diretamente pelo povo. Na primeira eleição dupla a diferença entre Netaniahu e Peres foi ínfima. Pode-se dizer então que neste caso, apesar de representar maioria, o primeiro-ministro já começa o mandato enfraquecido pela pouca diferença obtida. Ao contrário da terceira eleição entre Sharon e Barak, onde a diferença (24.8\%) é considerável, e o primeiro-ministro recebeu de facto o apoio da população em geral. Se formos comparar a eleição entre Netaniahu e Peres com a dos presidenciáveis norte-americanos Bush e Al Gore, verificamos que, mesmo com sistemas diferentes (e há uma clara discórdia entre os estudiosos em relação ao novo sistema eleitoral de Israel pósreforma) os dois (Netaniahu e Bush) começaram enfraquecidos, pela nítida divisão quase-igualitária dos eleitores.

Outra questão central é sobre o tipo de governo formado, seja ele minoritário, surplus ou minimal winning coalitions (mwc). Laver e Schofield constatam que $1 / 3$ de todos os governos europeus são minoritários, $1 / 4$ são surplus, e cera de $40 \%$ com mwc. ${ }^{23}$ Quanto a Israel, desde a reforma ela é geralmente surplus: no governo de Netaniahu (1996) o governo era formado por 66 parlamentares (+ 2 apoiando de fora), no de Barak (1999) por 75, e no de Sharon (2001) por 78, acrescidos de 4 posteriormente (neste, extraordinariamente os dois partidos maiores fazem parte, algo raro de acontecer).

Governos minoritários não são piores ou melhores que outros tipos de governo, tanto na formação de governos como em performance, ${ }^{24}$ ou até mesmo no que se refere à sobrevivência de democracias parlamentares. ${ }^{25}$ Laver e Schofield argumentam que o que real-

23 Op.Cit., Laver e Schofield, p. 70-1.

24 Sтвом, Kaare. Minority Government and Majority Rule, UK: Cambridge Univ. Press, 1990.

25 Warwick, P. V. Government Survival in Parliamentary Democracies, UK: Cambridge Univ. Press, 1994. 
mente importa não é a nomenclatura que o governo leva, se minoritário, surplus, ou mwc, mas o apoio efetivo que ele tem dentro do Legislativo ${ }^{26}$ (mesmo que não tenha no próprio governo). Sendo assim, a presença de governos surplus em Israel pós-reforma nada diz sobre sua estabilidade. Pelo contrário, como Israel vive períodos cruciais de sua história, nos quais pode por muitas vezes definir situações que modifiquem o contexto do país, é tido como imprescindível que os governos sejam os mais amplos possíveis para que haja "legitimidade representacional" no Parlamento nos momentos críticos de decisão e definição de tratados de paz e acordos com países e povos que estavam/estão em conflito com Israel.

Porém, esta suposta "legitimidade representacional" é sentida como instabilidade governamental, já que montar uma coalizão de governo, com vários partidos (inclusive vários pequenos), e alinhar um plano de governo único com ideologias tão divergentes, é uma proeza difícil de alcançar, e qualquer conflito de interesses pode gerar crise e instabilidade, fragilizando o governo além de dividir o bolo em mais partes, já que cada membro da coalizão quer sua fatia por nela participar, seja em office, em policy ou em recursos.

\section{Conclusão}

A reforma no sistema eleitoral provou ser errônea, dado os objetivos almejados e os respectivos resultados até o momento. Apesar de a reforma ser recente, há indícios suficientes de que ela continuará neste trajeto equívoco, e até se radicalizará.

Há perigos em qualquer mudança, pois pode-se alterar alguns fatores vantajosamente enquanto, de outro lado, os efeitos colaterais sufocam a democracia. Por exemplo, em se tentando reduzir o número de partidos que entram no Parlamento pode-se elevar a taxa atual de $1.5 \%$ a $4 \%$. Com isso, partidos minúsculos e até mesmo pequenos não conseguirão o teto mínimo exigido, porém os eleitores serão menos representados, afetando portanto valores democráticos.

Haviam as opções de reformar o sistema eleitoral e de continuar no status quo. Frente à mudança ocorrida, o melhor seria continuar no

26 Op. Cit., Laver e Schofield, p. 88. 
sistema anterior. Porém, dizer isso depois de obter os resultados é fácil. O difícil é analisar e prever antecipadamente o que determinada reforma acarretará no sistema.

Vários políticos dos dois maiores partidos tentam retornar ao sistema anterior, mas até que isso ocorra (se ocorrer), levará algum tempo. Nisso, o país perdeu anos em que um sistema eleitoral equivocado pode ter sido o responsável por atrocidades cometidas como resultados de políticas decididas por governos alternativos.

Vimos que a história política de um país foi mudada, juntamente com o sistema eleitoral. Nas três eleições que ocorreram no pós-reforma, o Partido Trabalhista era o maior partido, porém, em duas delas quem formou o governo foi o Likud. Um país como Israel, onde os conflitos intra-societários e externos são exacerbados, poderia caminhar por outros rumos caso o mesmo resultado das eleições tivessem sido calculados sem as reformas ocorridas. Portanto, vemos que instituições importam sim, e muito! Como afirmam Shepsle e Bonchek, "institutions matter!". Isto é, caminhos institucionais de condução de método de voto para solucionar um problema da escolha social afetam drasticamente esta mesma escolha social. ${ }^{27}$ Existia um problema nacional de insatisfação da sociedade em geral em relação ao sistema eleitoral que não mais atendia as necessidades para as quais foi criado. Mudou-se o sistema, porém os resultados foram contrários aos objetivos que ele deveria atender.

Os filósofos políticos Barry e Hardin diferenciam o homem da sociedade como "homem racional e sociedade irracional" quando não é nem um pouco evidente o que é melhor para o grupo (ou o que a maioria pensa que é melhor ao grupo), e mais importante ainda são os procedimentos institucionais pelos quais o grupo determina que são críticos em se optar pela escolha. ${ }^{28}$ Com base no resultado da reforma, podemos interpretar via rational choice que um grupo de indivíduos racionais podem produzir coletivamente resultados irracionais, mesmo que cada indivíduo do grupo tenha preferências que são consistentes (completas e transitivas). O teorema de Arrow adverte contra atribuir características individuais, como racionalidade, a grupos.

27 Op. Cit., Shepsle e Bonchek, p. 44.

28 Ibid., p. 48. 


\section{Referências bibliográficas}

Andersen, R.; YAISH, Meir. Social cleavages, electoral reform and party choice: Israel's 'natural' experiment. Centre for Research into Elections and Social Trends (CREST), Working paper n. 89, set. 2001. Disponivel em: <http:/ /www.crest.ox.ac.uk/index.htm/>.

Cheibub, J. A.; Przeworski, A.; Saiegh, S. Government Coalitions under Presidentialism and Parlamentarism. Presented at the Conference on Brazilian Political Institutions in Comparative Perspective: The Role of Congress in Presidential Systems, Centre for Brazilian Studies, Oxford University, 2001.

.; LIMONGI, F. Democratic institutions and regime survival: parliamentary and presidential democracies reconsidered.

$\mathrm{CNN}$. A guide to the Israeli election: nation votes in a special prime-minister election for the first time, 2001. Disponivel em: <http://cnn.com/indepth_specials/ $>$.

ELAZAR, Daniel J. Electoral reform for Israel: a realistic proposal. Jerusalem Center For Political Affairs. Disponível em: <http://www.jcpa.org/djeindex.htm/>.

HALPER, Jeff. Beyond the Bibi bill: Israel's electoral system and the Intifada. Disponível em: <http://www.merip.org/pins/pin2.html/>. Acesso em: 19 dez. 2000.

HazAN, R. Y. Centre parties: polarization and competition in european parliamentary democracies. Biddles Press, 1997.

HINCH, M. J.; Munger, M. M. Analytical politics.

LAVER, M.; SHePsLE, K. A. Making and breaking governments: cabinets and legislatures in parliamentary democracies. Cambridge University Press, 1996.

.; SCHOFIELD, N. Multiparty government: the politics of coalition in Europe. University of Michigan Press, 1990.

LiJPHART, A. Dimensions of ideology in the european party system. In: MalR, Peter (Ed.). The west european party system. Oxford University Press, 1990.

Electoral systems and party systems: a study of twenty-seven democracies 1945-1990. Oxford University Press, 1994.

MAHLER, Gregory. Israel's new electoral system: effects on policy and politics, middle east review of international affairs, 1(2), july 1997. Disponível em: $<$ http://meria.idc.ac.il/>

MaIR, Peter (Ed.). The west european party system. Oxford University Press, 1990.

Nachmias, David; Sened, Itai. Electoral reform in Israel. Disponível em: $<$ http://www.aceproject.org/main/english/es/esy_il.htm/>. 
PETERS, Joel. Under Netaniahu: the current situation in Israeli politics, Middle East Review of International Affairs, 1(1), january 1997. Disponivel em: $<$ http://meria.idc.ac.il/journal/1997/issue1/jv1n1a2.html/>

Shepsle, K.; BoncheK, M. Analysing politics. New York: W. W. Norton, 1997.

STOLL, Heather. Taking regime type seriously: theories of party sistems revisited. Stanford University Press, 2001.

STROM, Kaare. Minority government and majority rule. Cambridge University Press, 1990.

WARWICK, P. V. Government survival in parliamentary democracies. Cambridge University Press, 1994. 